\title{
Meckel's Diverticulum: A Cause of Obscure Gastrointestinal Bleeding Diagnosed by Double Balloon Enteroscopy
}

\author{
Asna Mohammed ${ }^{\mathrm{a}}$ Mariem Mohamed Mahmoud $^{\mathrm{a}}$ Labib Al-Ozaibi $^{\mathrm{b}}$ \\ Khaled Bamakhrama ${ }^{\mathrm{c}}$ \\ anternship, Rashid Hospital, Dubai, UAE; ${ }^{b}$ General Surgery Department, Rashid Hospital, Dubai, UAE; \\ 'Gastroenterology Department, Rashid Hospital, Dubai, UAE
}

\section{Keywords}

Obscure gastrointestinal bleeding · Meckel's diverticulum .

Double balloon enteroscopy

\begin{abstract}
Obscure gastrointestinal bleeding (OGIB) accounts for a small percentage of gastrointestinal (GI) bleeding. The underlying etiology includes small bowel lesions such as Meckel's diverticulum, a differential to be considered in a young adult. Capsule endoscopy and double balloon enteroscopy (DBE) are important imaging modalities used in the evaluation of OGIB. We describe a case of a young adult male who presented with bleeding per rectum. Upper and lower Gl endoscopies were negative and the patient was labeled to have OGIB. After further investigations, our patient was finally diagnosed to have Meckel's diverticulum by $\mathrm{DBE}$, strengthening its diagnostic utility.
\end{abstract}

$$
\begin{aligned}
& \text { () } 2020 \text { The Author(s) } \\
& \text { Published by S. Karger AG, Basel }
\end{aligned}
$$

\section{Introduction}

Obscure gastrointestinal bleeding (OGIB) is defined as recurrent or persistent gastrointestinal (GI) bleeding from an origin that cannot be identified using upper or lower endoscopy. It accounts for approximately $5 \%$ of pa- tients presenting with GI hemorrhage overall [1]. OGIB is mostly caused by small bowel lesions with underlying etiologies that include vascular, inflammatory, iatrogenic, tumors, and diverticular disorders, including Meckel's diverticulum (MD) [1].

Therefore, endoscopic techniques that image the small bowel, including capsule endoscopy (CE) and deep enteroscopy, are commonly used in the evaluation of such cases [2]. While both are useful imaging modalities, in this report, we describe a case of OGIB that was evaluated by various diagnostic tools with the end diagnosis of MD by double balloon enteroscopy (DBE). We demonstrate further evidence to current literature in regards to the usefulness of such techniques, as well as an additional perspective on MD specifically.

\section{Case Report/Case Presentation}

A 22-year-old male, with no previous medical or surgical history, presented to the emergency department with 1-day history of bleeding per rectum preceded by mild abdominal pain. The bleeding was described as fresh blood with clots. There was no history of vomiting, fever, or recent changes in bowel habits.

On examination, he was hemodynamically stable with hemoglobin of $11.1 \mathrm{~g} / \mathrm{dL}$. His abdomen was soft, non-tender, and nondistended. Rectal examination was positive with small amount of dark blood. Proctoscopy revealed blood in the rectum. His hemoglobin eventually dropped to $7.4 \mathrm{~g} / \mathrm{dL}$, and he required blood karger@karger.com www.karger.com/dmj

Karger $\stackrel{\text { ' }}{=}$

BOPEN ACCESS
(C) 2020 The Author(s)

Published by S. Karger AG, Basel

This article is licensed under the Creative Commons AttributionNonCommercial-NoDerivatives 4.0 International License (CC BYNC-ND) (http://www.karger.com/Services/OpenAccessLicense). Usage and distribution for commercial purposes as well as any distribution of modified material requires written permission.
Asna Mohammed

Rashid Hospital

PO Box 4545 315, Umm Hurair Second

Dubai (United Arab Emirates)

asna_mhd@yahoo.com 


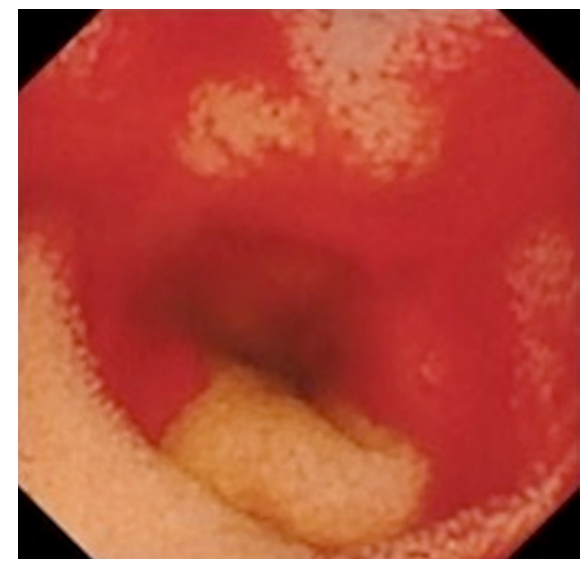

Fig. 1. CE showing fresh blood localized to the ileum. CE, capsule endoscopy.

transfusion. Upper and lower endoscopies were done and did not reveal an active source of bleeding. CT abdominal angiography was done to identify the source of bleeding; however, no clear source was found. CE subsequently showed fresh blood localized to the ileum (shown in Fig. 1). DBE was done to further image the small bowel and showed MD deep in the ileum with hyperemic mucosa at the base (shown in Fig. 2).

The patient was taken for laparoscopic excision of MD. Intraoperatively, $\mathrm{MD}$ ( $8 \mathrm{~cm}$ in length) was identified and a portion of the small bowel was resected with side-to-side anastomosis (shown in Fig. 3).

The patient had an unremarkable postoperative recovery with complete resolution of his symptoms. Histopathology report later confirmed Meckel's diverticulitis with gastric heterotopia.

\section{Discussion/Conclusion}

When patients present with GI bleeding, initial evaluation often includes endoscopy. It is understood, however, that the underlying etiology may not always be evident during the preliminary assessment. OGIB is defined as bleeding from an unidentified source that persists or recurs after an initial negative endoscopic evaluation [1].

The most common cause of OGIB in older patients is angiectasias of the small bowel. Tumors are considered the most common cause of OGIB in patients $<50$ years old. Ulceration associated with Meckel's diverticulum is seen notably in younger patients. Various other causes that are associated with OGIB include NSAIDs enteropathy, inflammatory bowel disease, radiation enteropathy, and Dieulafoy's lesions [1].

Overall, the majority of cases of OGIB are attributed to small bowel lesions. In spite of this, missed lesions in endoscopy are also a source of OGIB [3]. As standard prac-

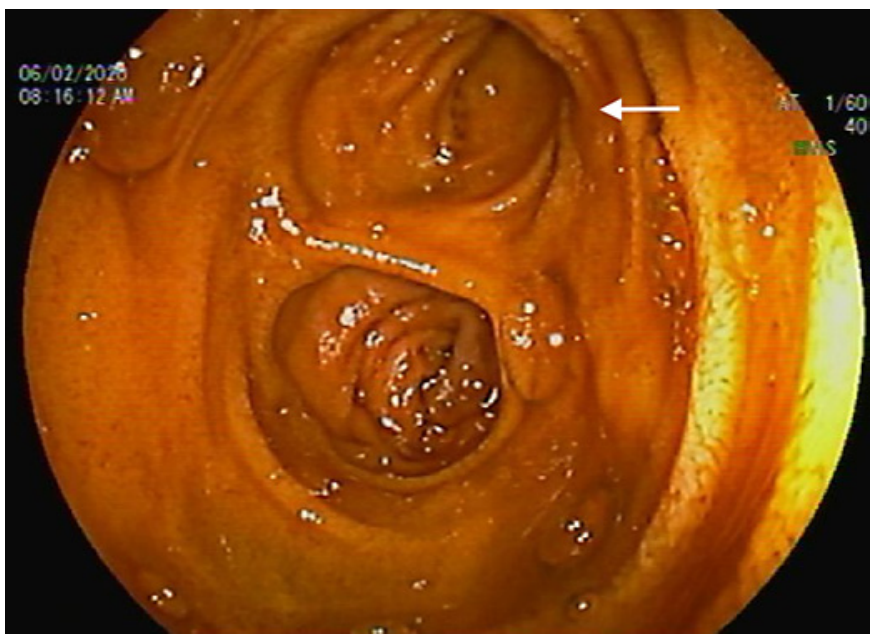

Fig. 2. DBE showing Meckel's diverticulum in the ileum (white arrow pointing to diverticulum). DBE, double balloon enteroscopy.

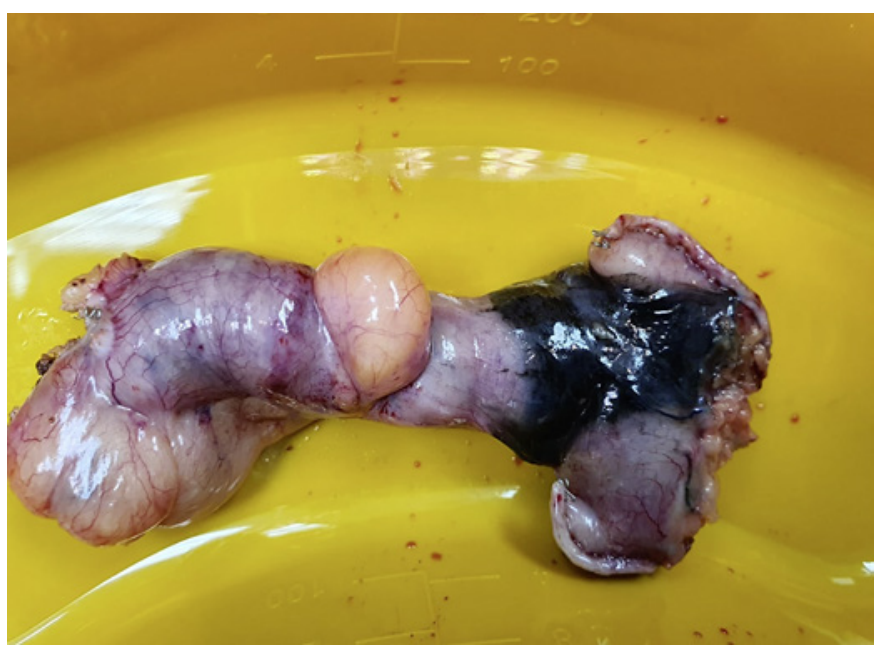

Fig. 3. Gross appearance of Meckel's diverticulum after laparoscopic excision.

tice, either a repeat endoscopy or small bowel imaging modalities are considered suitable options in the next step of evaluation. Because of the well-known limited capacity to evaluate the small bowel using endoscopy, further imaging modalities of the small bowel have come into attention, notably CE and DBE [2]. As patients remain hemodynamically stable, the first test obtained is usually CE. If bleeding continues or recurs, CT enterography or MR enterography should be obtained to identify an active source of bleeding. If no source is identified and the bleeding continues, the next step is typically deep enteroscopy [4].

Numerous studies have been done to compare CE and $\mathrm{DBE}$ in their diagnostic value in OGIB with variable re- 
sults. In some studies, CE has proven to have a higher diagnostic utility than DBE but in others found to be similar [5]. A meta-analysis done comparing DBE and CE for OGIB found DBE to be of more diagnostic value when performed in patients with a positive CE [5]. Hence, CE could even be thought of as a useful screening tool prior to DBE in patients with OGIB [1]. In our case, DBE provided the most conclusive information regarding the etiology of bleeding and guided further management.

Similar cases of MD have been reported in which young adults presented with GI hemorrhage and initial investigations such as upper, lower GI endoscopies and angiography were negative; the patients were subsequently diagnosed to have MD by DBE. In one such case reported by Taniuchi et al. [6], CE was done after initial investigations and identified oozing hemorrhage in the ileum. DBE was then done and identified a diverticulum. This further stresses the importance of these two modalities in assessing the small bowel and in diagnosing the cause of OGIB, specifically MD.

MD is the most common congenital GI malformation, typically clinically silent and found incidentally. Clinical manifestations in adults include GI bleeding, obstruction, or intussusception [7]. While an uncommon etiology, it should be a differential in a young adult who presents with OGIB.

Conventional modalities used in the diagnosis of MD include Meckel's scan. However, the sensitivity in adults has been found to be less compared to the pediatric population, and in addition, there are various factors that contribute to the false-negative rate with the use of Meckel's scan [8]. With improved techniques to visualize the small bowel, the trend in diagnosing MD has shifted. The usefulness of $\mathrm{DBE}$ in diagnosing $\mathrm{MD}$, for example, has been described in the literature $[9,10]$. One study resulted in $86.5 \%$ diagnostic yield of preoperative DBE and even found it to be more reliable than CE for the diagnosis of suspected MD [10]. While there have been numerous studies done in the comparison of small intestine imaging modalities as an etiology of OGIB, there have been comparatively less studies done to compare $\mathrm{CE}$ and $\mathrm{DBE}$ in specifically diagnosing MD.

In a young adult who presents with OGIB such as in the present case, it is important to consider MD as a differential. In our case, retrospectively, we highlighted the diagnostic utility of both $\mathrm{CE}$ and $\mathrm{DBE}$, specifically the $\mathrm{DBE}$, which gave us a final diagnosis with the $\mathrm{CE}$ as a supportive modality.

\section{Statement of Ethics}

Informed written consent was obtained from the patient for publication of the case details.

\section{Conflict of Interest Statement}

The authors have no conflicts of interest to declare.

\section{Funding Sources}

No source of funding or sponsor.

\section{Author Contributions}

A.M. and M.M. contributed to writing and data collection. L.A. contributed to study design and review. K.B. contributed to study review.

\section{References}

1 Ohmiya N, Nakagawa $Y$, Nagasaka $M$, Tahara T, Shibata T, Nakamura M, et al. Obscure gastrointestinal bleeding: diagnosis and treatment. Dig Endosc. 2015;27(3):285-94.

2 Maeda Y, Moribata K, Deguchi H, Inoue I, Maekita T, Iguchi M, et al. Video capsule endoscopy as the initial examination for overt obscure gastrointestinal bleeding can efficiently identify patients who require doubleballoon enteroscopy. BMC Gastroenterol. 2015; 15:132.

3 Otani K, Watanabe T, Shimada S, Hosomi S, Nagami Y, Tanaka F, et al. Clinical utility of capsule endoscopy and double-balloon enteroscopy in the management of obscure gastrointestinal bleeding. Digestion. 2018;97(1):528.

Meckel's Diverticulum Diagnosed by Double Balloon Enteroscopy
4 Cave D. Evaluation of suspected small bowel bleeding (formerly obscure gastrointestinal bleeding). In: Saltzman UTDJR, Travis AC, editors. Waltham, MA: UpToDate Inc; 2020.

5 Teshima CW, Kuipers EJ, van Zanten SV, Mensink PB. Double balloon enteroscopy and capsule endoscopy for obscure gastrointestinal bleeding: an updated meta-analysis. J Gastroenterol Hepatol. 2011;26(5):796-801.

6 Taniuchi K, Tanaka H, Iwamura S, Mori I. Meckel's diverticulum preoperatively diagnosed by double-balloon endoscopy. Intern Med. 2012;51(9):1023-6.

7 Hosn MA, Lakis M, Faraj W, Khoury G, Diba S. Laparoscopic approach to symptomatic meckel diverticulum in adults. JSLS. 2014; 18(4).
8 Pattni V, Wright K, Marden P, Terlevich A. Meckel's diverticulum in an adult: an obscure presentation of gastrointestinal bleeding. BMJ Case Rep. 2016;2016:bcr2015213852.

9 Fukushima M, Kawanami C, Inoue S, Okada A, Imai Y, Inokuma T. A case series of Meckel's diverticulum: usefulness of double-balloon enteroscopy for diagnosis. BMC Gastroenterol. 2014;14:155.

$10 \mathrm{He}$ Q, Zhang YL, Xiao B, Jiang B, Bai Y, Zhi FC. Double-balloon enteroscopy for diagnosis of Meckel's diverticulum: comparison with operative findings and capsule endoscopy. Surgery. 2013;153(4):549-54. 